\title{
Evidence and the health policy process: from traditional evidence hierarchy to inclusive and multi-source methodology
}

\author{
Francesca Celletti ${ }^{1}$, Anna Wright ${ }^{2}$, Eric Buch ${ }^{3}$, Badara Samb ${ }^{4}$ \\ 1. University of Pretoria, Gezina, University of Pretoria, South Africa. 2. Freelance Consultant, Health Policy and Planning, \\ London, United Kingdom. 3. Faculty of Health Sciences, Gezina, University of Pretoria, South Africa. \\ 4. Political and Public Affairs Branch, UNAIDS, Geneva, Switzerland
}

Correspondence: Francesca Celletti. Address: 31 Bophelo Road, Gezina, University of Pretoria, South Africa.

E-mail: francesca.celletti@gmail.com

Received: February 16, 2013

Accepted: March 24, 2013

Online Published: April 6, 2013

DOI : 10.5430/jha.v2n3p106

URL: http://dx.doi.org/10.5430/jha.v2n3p106

\section{Abstract}

Calls for evidence-based health policy have gathered force as an extension of the movement for evidence-based medicine. In clinical medicine, major investment has been made in efforts to systematize the collection and analysis of data and distinguish effective interventions from those that are less likely to work. In contrast, there is little consensus on what data are needed and what research methods are suitable and acceptable to produce a robust evidence base for social policy in the health sector. Evidence gathering for health policy must synthesize diverse sources, recognize the extent to which context influences policy outcomes, accommodate potentially conflicting interests and be flexible enough to respond to the time and resources pressures that are at play. Despite the challenges, there is scope for the development of a methodology that can draw on a wide range of evidence sources while retaining sufficient scientific rigor. These sources should extend from data generated using causal methods (randomized controlled trials) to information that can shed light on the many contextual and political issues that are also pertinent to health policy decision making.

\section{Key words}

Evidence-based decision making, Public health interventions, Health policy development, Health policy research

'Both thinking and facts are changeable, if only because changes in thinking manifest themselves in changed facts. Conversely, fundamentally new facts can be discovered only through new thinking ${ }^{[1]}$.

\section{I ntroduction}

In 1863, President Abraham Lincoln established the National Academy of Sciences to get advice on technical matters from the leading thinkers in the United States ${ }^{[2]}$. This early attempt to strengthen the influence of scientific research on decision making marked the beginnings of an interest in evidence based policy as a reaction to decision making driven entirely by conviction. 
Since then, the pursuit of evidence-based medicine which uses scientific methods, particularly from the field of epidemiology, in decisions for the care of individual patients has transformed clinical practice in medicine.

Today, calls for an equivalent transformation to achieve evidence-based health policy dominate international, national, and regional health meeting agendas and the term "evidence of effectiveness" has become a central part of health policy dialogue. Moreover, national health plans in many countries cite evidence of program effectiveness as requisite for considering interventions to meet national health goals. However, in the shift from an individual-clinical to a population-policy level, the decision-making context becomes more uncertain, variable and complex ${ }^{[3]}$.

\section{Evidence for clinical practise decisions versus evidence for policy making}

\subsection{Evidence for clinical practice}

In clinical medicine, the diversity of sources and quantity of available data has grown exponentially along with the expansion of information technologies and an emphasis on the need for cost-effectiveness. Methods for synthesis of research information have been developed to accommodate the quantity and complexity of the information now available for guiding clinical practice decisions ${ }^{[4]}$. Large bodies of research information are assimilated using systematic reviews that apply "strategies that limit bias in the systematic assembly, critical appraisal, and synthesis of all relevant studies on a specific topic" ${ }^{[5]}$. The Cochrane Collaboration and the U.S. Preventive Services Task Force are among several groups that have systematized evidence-based approaches. These efforts have been designed to distinguish effective interventions from those that are less likely to work and to highlight voids in knowledge.

However, the traditional hierarchy that places information from systematic reviews of randomized controlled trials at the pinnacle has been criticized for being too narrow and the supremacy of the randomized controlled trial as a research design is increasingly challenged ${ }^{[6]}$. Inherent methodological issues that contribute to limited applicability in clinical situations have been exposed, particularly by proponents of "personalized medicine" ${ }^{[7-10]}$. Evidence that demonstrates unwarranted variation in outcomes from the same proven clinical interventions delivered to similar patients adds weight to the argument that other considerations including process, quality, and the psychological and social aspects of illness as well as the preferences of patients all play a role alongside clinical efficacy ${ }^{[11]}$.

Many commentators argue for the value of individual clinical judgment and patient preferences and challenge the received wisdom that the best evidence is necessarily either objective or clinical ${ }^{[6,12-14]}$.

Wayne Jonas proposes replacing the evidence hierarchy for clinical decision making with an "evidence house" that can also accommodate information about the relevance of medicine for patients, broader contextual realities, or the generalizability of an intervention in health systems. This model affords greater accessibility to a wider range of information and also assigns value to types of qualitative and non-causal data that have traditionally been held in lower regard6. As such, this more expansive approach to evidence gathering begins to address the needs of those who have to shape population level, rather than patient level, policy decisions and may have to integrate experience, judgment and expertise with the best available external evidence from systematic research ${ }^{[15]}$.

\subsection{Evidence for health policy}

At the theoretical level, debate around issues of knowledge creation is long-running and wide-ranging. Some philosophers have questioned whether evidence sufficient for knowledge can necessarily be considered truth ${ }^{[15]}$. Others have explored the ways that power and ideology may play out in the production, selection and interpretation of evidence ${ }^{[6,16,17]}$. 
Socio-political processes often influence the priorities agenda and historical and cultural values can shape currently acceptable theories and paradigms.

At a practical level, those responsible for social policy, specifically health policy, need to take into consideration many forms of evidence other than scientific research on clinical effectiveness. As well as published research findings, the opinions values and preferences of those who will either feel the impact of the intervention or play a role in implementation are also relevant to decision making. To these ends, some mechanisms for bringing rigor to the evidence provided through expert opinion have been developed. The Delphi Method and the Nominal Group Technique are two structured communication techniques used in health policy development ${ }^{[18,19]}$. They do not, however, offer a methodology for incorporating the findings from the consultation process with other types of evidence.

Similarly, while the "evidence house" promotes a more inclusive base, the model does not propose a method for synthesizing the different sources of evidence in any systematic manner ${ }^{[6]}$.

As of today, an understanding of how scientific evidence interacts and contributes to the many other sources of knowledge for decision making has not been adequately explicated.

\section{Evidence for health policy - the current state of the art}

Health policy still lacks a commonly accepted and robust method for information synthesis. Research evidence, especially from the social world, is unlikely to be sufficiently clear-cut and unambiguous to be translated directly into policy. It cannot be assumed that existing knowledge is available when a decision is to be made; that the relevant policy maker is able to access and understand it; or that all other factors shaping the policy process can be held constant while evidence is located.

Moreover, policy decisions are often political or ideological as well as scientific in nature and thus cannot be tackled as directly and comprehensively by research as can questions pertaining to clinical medicine. Data are open to multiple interpretations, which are shaped by the personal and professional values of the interpreter and by the social contexts within which research findings are to be applied.

When it comes to making immediate policy decisions, a range of criteria are often relevant including budgetary constraints and competing claims on resources, experiential knowledge and national and local policy guidance. A balance is sought between different interests and the influence that evidence has on policy decisions is inevitably mediated by the judgment of the policy makers and the context in which they are operating.

The words of William Gorham ${ }^{[20]}$, describing why a major North American social science initiative in the mid-1960s had "failed" to produce the expected impact on policy and social life, illuminate this point well. "No amount of analysis is going to tell us whether the nation benefits more from sending a slum child to preschool, providing healthcare for an old man or enabling a disabled housewife to resume her normal activities. The grand decisions—how much health; how much education; how much welfare and which groups of the population shall benefit—are questions of value judgments and politics".

In general terms, for a given health policy intervention — whatever the subject — studies evaluating its effectiveness are identified, collected, and assessed in terms of their quality ${ }^{[21,22]}$. The main effects of the intervention are summarized, intervention characteristics that influenced effectiveness are described, barriers to implementation and unintended consequences of the interventions are detailed, and costs are estimated where data is available. Then, depending on the availability and strength of the evidence, a recommendation is made for or against an intervention, or it is determined that the evidence is insufficient to draw a conclusion ${ }^{[21,22]}$. 
However, most of the evidence available on health policy interventions does not directly analyze the correlation between a given intervention and the direct impact on a specific outcome. This is usually because of the complexity of the context and the presence of other confounding and interacting factors that can impact the final outcomes ${ }^{[23]}$. The impact of interventions on outcomes is not the only gap in evidence. To make things more difficult, interventions shown to work in specific settings or with individuals or small groups may prove difficult to evaluate when implemented on a broader community scale when more complex processes of social change must be taken into account ${ }^{[24]}$. In the health sector some argue that there is a tendency to generate policy interventions that are informed by a universal perspective ${ }^{[25]}$ and normative constructs will often supplant local knowledge and deny the complexity of practical realities ${ }^{[23]}$. Moreover, interventions found to be highly effective at one point in time may be less effective at a later date if the conditions that contributed to their effectiveness have changed. Likewise, the feasibility of implementing interventions may change over time. Finally, endpoints for determining program success may change. As years accrue to allow evaluation of more distal outcomes (e.g. morbidity and mortality), earlier intermediate outcomes may no longer be the yardstick for judging intervention success.

In low income countries in particular, policy decisions are being made in the context of extreme resource limitations and must take into account a wide gap between needs and resources, expectations and performance ${ }^{[26]}$.

Often, information on context — culture, local norms, history, resources, and constraints — as well as the validity of the data in different environments and transferability of the results, especially impact, requires collection of new data that may be either quantitative or qualitative. In addition, implementation of evidence-based programs often results in a tension between fidelity (maintaining the original program design) and re-invention (changes needed for replication in a new setting). Increasingly, participatory processes are being used with evidence-based efforts to understand local context while maintaining some degree of fidelity ${ }^{[27]}$, applying program-planning frameworks, engaging the community in decision making, conducting sound evaluations, and disseminating what is learned.

Finally, health policy should not only focus on the content of reform, but also pay attention to the actors involved in policy reform (at the international, national and sub-national levels), the processes contingent on developing and implementing change and the context within which policy is developed ${ }^{[25]}$.

In view of the multiplicity and complexity of knowledge types and sources that are relevant, health policy makers wishing to ensure that decisions are supported by evidence need to access research that combines many studies and sources with different methods and results to identify consistencies in a set of findings ${ }^{[28,29]}$.

Research synthesis is therefore widely used to inform decision making at global and national level.

However, we still lack an agreed and standardized method for such synthesis. With no recognized framework for assigning value to different data or systematizing the incorporation of diverse sources and considerations, attempts to apply evidence-based decision making to health policy development can often resort to an ad hoc assimilation of information that is necessary but is not sufficient. For those bearing responsibility for policy decisions, a synthesis approach to evidence creation cannot provide the security and protection that is available for those who can cite the evidence produced by more traditional methods such as systematic review or randomized controlled trials to support clinical decisions.

\section{A methodology for synthesizing sources, factoring in context and balancing interests}

How can evidence-based decision making for health policy be best achieved in the light of incomplete scientific data, multiple additional sources of information and recognizing the influence of other pressures? It is unrealistic to demand that every decision be based on robust scientific evidence from systematic reviews when we know we are far from having all the information we need and that many other factors are also at play in developing sound policy. 
For this, we need to apply an innovative approach that can blend, weigh and synthesize all available information: research; assessment data on the magnitude of the problem; appraisal of the effects of the problem; epidemiologic data on determinants; stakeholder opinion on the nature of the problem and acceptable solutions; existing practices and traditions; less robust yet promising intervention evaluations; program options within budgetary constraints; legal considerations; regulatory frameworks; the political will to address the issues ${ }^{[30-32]}$; and finally the clinical, public health, social, and development consequences of not taking such a decision.

Interspersing data gathering with consultation among stakeholders is common practice for national governments and international organizations alike, and many organizations have developed their own rigorous practices and standards for ensuring that research evidence is reviewed and discussed by a wide range of individuals as part of the process of policy development ${ }^{[22]}$. Nevertheless, in the health policy arena the part played by expert judgment and the influence of stakeholder opinion, values and preferences generally functions as a discreet political process that mediates between research findings and final policy decisions or guidelines (often disrupting the integrity of the scientific evidence) ${ }^{[33]}$. Sources beyond the published scientific literature are perceived as ideology, or as pragmatism; not as evidence. A new model must seek to systematize the collection of such contextual knowledge and incorporate these contributions into the evidence base in as scientific a manner as possible.

To these ends we propose a model for the production of evidence for health policy (Figure 1).The model strives to ensure an inclusive base for health policy making by adopting an expansive technique that can accommodate a wide range of sources, including those that elicit opinions values and preferences, but applies a systematic approach to the collection and incorporation of these less "scientific" sources. Thus the funnel narrows and expands in a linear series of data gathering surges that are synthesized and then further expanded and enriched as the process continues.

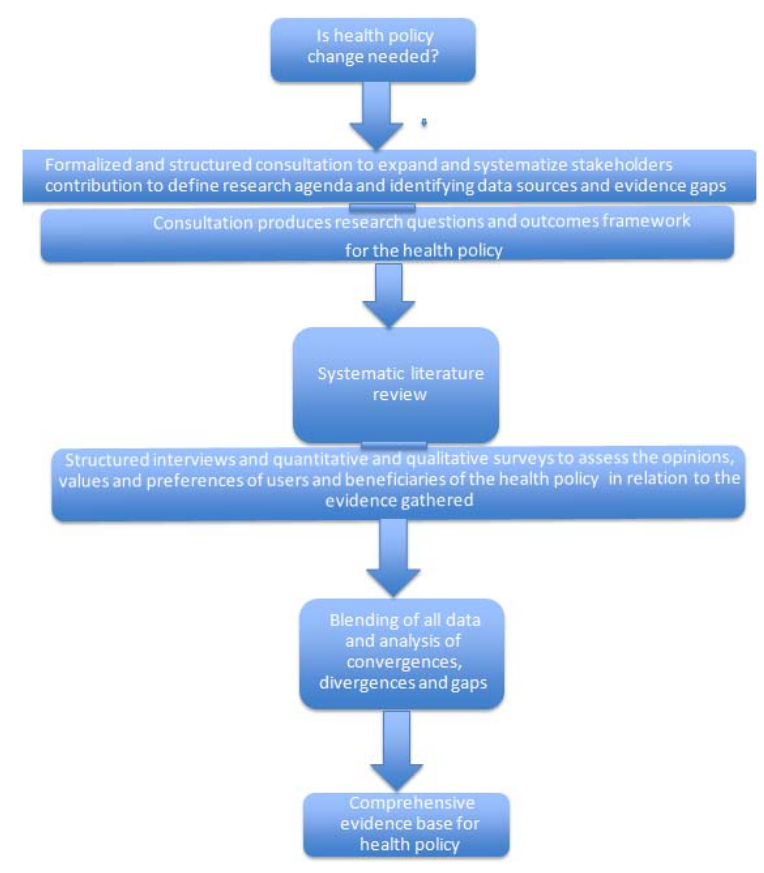

Figure 1. Model for the production of evidence for health policy

The proposed model is generic and needs further refinement and experimentation. It has the disadvantage of being a resource-intensive approach to evidence production due to the large number of people that must be involved and consulted. On the other hand, the dynamic nature of the model means the time from identification of the need for evidence 
to the production of a sufficiently robust evidence base on which to base policy discussions need not be as great as that needed for the production of data through other research techniques such as controlled trials. In this model, the policy discussion thus does not start as a separate activity at the end but is built in as part of a vibrant and evolving process and thus the evidence produced is more useful and relevant to policy making.

\section{Conclusion}

An accepted framework that can encompass a wider range of relevant sources in a manner that is nevertheless systematic could help advance the evolution of appropriate and robust quantitative and qualitative research methods which depart from those that are used for the evaluation of clinical actions. In particular, it could assist understanding of how to evaluate the impact of interventions in the context of complex environments and with time-changing indicators and advance the cause of improvements in the conceptualization and operationalization of implementation science. The integration of expert judgment and of stakeholder opinions, values and preferences in a systematic manner will help to ensure that evaluation of program effectiveness takes into consideration the context in which the intervention is implemented and the various confounding factors.

\section{Conflict of interests}

All authors declare no conflict of interest

\section{Authors contribution statement}

Francesca Celletti conceptualized the paper, performed literature review, and wrote the first drafts; Anna Wright provided feedback on the design of the paper, performed literature review, and finalized the development of the manuscript; Eric Buch provided feed-back throughout the development of the paper; Badara Samb provided feed-back throughout the development of the paper.

\section{References}

[1] Fleck L Genesis and Development of a Scientific Fact. Chicago 1935. University of Chicago Press.

[2] National Academy of Sciences. Founding of the National Academy of Sciences [Internet]. Available from: http://www7.nationalacademies.org/archives/nasfounding.html. (Accessed December 6, 2004).

[3] Victora CG, Habicht JB, Bryce J. Evidence-based public health: moving beyond randomized trials. Am J Public Health. 2004; 94: 400-5. PMid:14998803 http://dx.doi.org/10.2105/AJPH.94.3.400

[4] Brownson RC, Fielding JE, Maylahn CM. Evidence-based public health: a fundamental concept for public health practice. Ann Rev Public Health. 2009; 30: 175-201. PMid:19296775 http://dx.doi.org/10.1146/annurev.publhealth.031308.100134

[5] Cook DJ, Sackett DL, Spitzer WO. Methodologic guidelines for systematic reviews of randomized control trials in health care from the Potsdam Consultation on Meta-Analysis (1995). J Clin Epidemiol. 1995; 48: 167-71. http://dx.doi.org/10.1016/0895-4356(94)00172-M

[6] Wayne J. The evidence house: How to build an inclusive base for complementary medicine. West J Med. $2001 ; 175$ (2): $79-80$. http://dx.doi.org/10.1136/ewjm.175.2.79

[7] Giordano J. Good as gold? The randomized controlled trial - paradigmatic revision and responsabilities in pain research. American Journal of Pain Management. 2006; 16(2): 66-69.

[8] Bell IR, Caspi O, Schwartz GE, Grant KL, Gaudet TW, Rychener D, Maizes V, Weil A. Integrative medicine and systemic outcomes research: issues in the emergence of a new model for primary health care. Arch Intern Med. 2002; 162(2): 133-40. PMid:11802746 http://dx.doi.org/10.1001/archinte.162.2.133

[9] Caspi O, Bell IR. One size does not fit all: aptitude x treatment interaction (ATI) as a conceptual framework for complementary and alternative medicine outcome research. Part 1--what is ATI research? J Altern Complement Med. 2004; 10(3): 580-586. PMid:15253866 http://dx.doi.org/10.1089/1075553041323812

[10] Boswell MV, Giordano J. Evidence-based or evidence-biased: the need to re-appraise and re-align levels of information with stakeholder values. Pain Physician. 2009; 12(2): 283-286. PMid:19305479 
[11] The Dartmouth Atlas. Cardiac Surgery. 2005 [Available from: www.dartmouthatlas.org/downloads/reports/Cardiac_report_2005.pdf.)

[12] Mulley AGJ, Wennberg JE. Reducing unwarranted variation in clinical practice by supporting clinicians and patients in decision making. In: Gigerenzer G, Gray M, editors. Better Doctors, Better Patients, Better Decisions: Envisioning Health Care in 2020. USA: Cambridge MIT Press; 2010.

[13] Linde K, Jonas WB. Evaluating complementary and alternative medicine: the balance of rigor and relevance. In: Jonas WB, Levin JS, eds. Essentials of Complementary and Alternative Medicine. Philadelphia: Lippincott Williams \& Wilkins. 1999: 57-71

[14] Robert Almeder, Truth and Evidence, The Philosophical Quarterly. 1974; 24(97): 365-368.

[15] Davies PT. What is evidence-based education? British Journal of Educational Studies. 1999; 47: 108-21. http://dx.doi.org/10.1111/1467-8527.00106

[16] Lukes S. Power: A Radical View, Second Edition. Palgrave Macmillan. 2005.

[17] Krieger N. Emerging theories for social epidemiology in the 21st century: an ecosocial perspective. Int J Epidemiol. 2001; 30 (4): 668-677. PMid:11511581 http://dx.doi.org/10.1093/ije/30.4.668

[18] Sackman, H. Delphi Assessment: Expert Opinion, Forecasting and Group Process" in Brown, Thomas, "An Experiment in Probabilistic Forecasting", R-944-ARPA, 1972.

[19] Delbecq AL, VandeVen AH. A Group Process Model for Problem Identification and Program Planning. Journal of Applied Behavioral Science. 1971; VII: 466 -491. http://dx.doi.org/10.1177/002188637100700404

[20] Gorham W. Cited in Booth T. Developing policy research.1988. Aldershot: Gower: 97-8.

[21] Briss PA, Zaza S, Pappaioanou M, Fielding J, Wright-De Aguero L, Truman BI et al. Developing an evidence-based guide to Community Preventive Services—methods. Am J Prev Med. 2000; 18 (suppl 1): 35-43. http://dx.doi.org/10.1016/S0749-3797(99)00119-1

[22] The World Health Organization. Handbook for guideline development. 2008. The World Health Organization, Geneva. http://apps.who.int/iris/bitstream/10665/75146/1/9789241548441_eng.pdf (accessed 2 February 2013).

[23] Seckinelgin, Hakan.The international politics of HIV/AIDS: global disease-local pain. Routledge 2008, London, UK.

[24] McLeroy KR, Norton BL, Kegler MC, Burdine JN, Sumaya CV (2003). Community based interventions. Am J Public Health. 2003; 93: 529-33. PMid:12660190 http://dx.doi.org/10.2105/AJPH.93.4.529

[25] McGregor, J.A. Researching Wellbeing: Communicating between the Needs of Policy Makers and the Needs of People. Global Social Policy 2004; 337-358. http://dx.doi.org/10.1177/1468018104047491

[26] Raleigh V. Health Policies in Developing Countries. BMJ. 1996; 312: 130.2

[27] Israel BA, Schulz AJ, Parker EA, Becker AB. Review of community-based research Annu Rev Public Health. 1998; 19:173-202. PMid:9611617 http://dx.doi.org/10.1146/annurev.publhealth.19.1.173

[28] Eriksson C. Learning and knowledge-production for public health: a review of approaches to evidence-based public health. Am J Public Health. 2004 March; 94(3): 400-405.

[29] Burchett H, Umoquit M, Dobrow M (2011). How do we know when research from one setting can be useful in another? A review of external validity, applicability and transferability frameworks. J Health Serv Res Policy. 2011; 16 (4): 238-44. PMid:21965426 http://dx.doi.org/10.1258/jhsrp.2011.010124

[30] Hutchinson E, Droti B, Gibb D, Chishingad N, Hoskins S, Phiri S et al. Translating evidence into policy in low-income countries: lessons from co-trimoxazole preventive therapy. Bulletin of the World Health Organization. 2011; 89: 312-316. PMid:21479096 http://dx.doi.org/10.2471/BLT.10.077743

[31] Brownson RC, Baker EA, Leet TL, Gillespie KN. Evidence-based public health. New York 2003: Oxford University Press. PMCid:1732269

[32] Glasgow RE, Klesges LM, Dzewaltowski DA, Bull SS, Estabrooks P. The future of health behaviour change research: what is needed to improve translation of research into health promotion practice? Ann Behav Med. 2004; 27: 3-12. PMid:14979858 http://dx.doi.org/10.1207/s15324796abm2701_2

[33] Shekelle B. Developing Guidelines. BMJ. 1999; 318: 593-599. PMid:10037645 http://dx.doi.org/10.1136/bmj.318.7183.593 